\title{
CONTINUITIES AND DISCONTINUITIES IN THE ORAL TRANSMISSION OF THE TIBETAN GESER EPIC
}

\begin{abstract}
For Tibetans, especially for the ones with a pastoral background, bardic performances represent a constant source of inspiration and identification. They establish continuity in preserving a Tibetan heritage. However, over the centuries they have tended to become a vehicle for carrying the ideologies of the rulers in power. Whether the oral performances of the Geser bards will cease to exist or whether their placement on the UNESCO Intangible Heritage List in 2009 will successfully safeguard the transmission of the Tibetan Geser epic remains an open question. In the Tibetan Autonomous Region of the People's Republic of China the orally reported sources remain manifold and the work on the publications of the many episodes of the epic continues. Therefore, it is certain that the Geser epic will retain its importance, even if it is yet to be seen which forms it will take on in the future.
\end{abstract}

Keywords: Tibetan Geser bards, performance, oral transmission

The Geser epic is recounted all over Central Asia, and Tibetan culture also relates to the epic and its king (rgyal po) in various ways. My research has focused on the role of Tibetan bards (ge sar sgrung mkhan) and their staged performances of the epic in the northern regions of the Tibetan Autonomous Region (TAR) of the People's Republic of China (PRC). ${ }^{1}$ It investigates the conditions and circumstances under which the epic of the Tibetan king Geser (Ge sar) has been transmitted by bardic performances from past generations up to the present day.

A few documented sources indicate that until the first half of the twentieth century government representatives, noble families, rich traders, and in some rare cases abbots of monasteries were the principal sponsors and patrons of these bards. By employing the most famous bards, these groups have also enabled a process of textualisation of the epic. Other sedentary bards were invited by local pastoralists to perform the epic at festivities in exchange for tea, food, and sometimes money. Vagrant bards sought sources of sustenance and inspiration by visiting pilgrimage sites [Rgyal mtsho 1990, Nebesky-Wojkowitz 1954: 33-34, and Yang 2017: 157-180]. During the Cultural Revolution (1966-1976), while the transmission of the Geser epic was prohibited and bards were prosecuted [e.g.: Jabb 2015: 69-75], certain political and religious movements started invoking the epic hero Geser [Diemberger 2005]. In the 1980s, it was the support of the Tenth Panchen Lama that launched a revival of bardic performances by the most famous bards [Wangdan 2017: 44], who were later invited to academic institutions of the TAR and further supported by well-educated Tibetans for performances and a continued textualisation of the Geser epic [Studer 2019: 160-163].

The epic is transmitted to "common" bards (sgrung mkhan) by learning (bslab sgrung) or by frequently listening to (thos sgrung) recitations of the epic from memory, public readings, or watching performances [Gcod pa 2000: 160-181, Rgyal mtsho 1990, Yang 1989]. In his landmark study, Stein [1959: 332] differentiates between these bards and visionary bards. My research [Studer 2020: 118-131] demonstrates that also in the nomadic and semi-nomadic areas of the Nagchu (Nag chu) and Chamdo (Chab mdo) Prefectures, the Geser epic may manifest itself in recurrent visionary dreams (rtogs pa nyams shar) to Tibetans who show certain inner (nang rkyen) and outer (phyi rkyen) predispositions. These dreams mostly occur at the time of adolescence or in contexts where these pastoralists herd their family's livestock in solitude in high-altitude rangelands. They understand their visionary experiences as requests to begin transmitting the Geser epic to their fellow countrymen. Religious specialists are then required to support these future visionary

${ }^{1}$ My research was made possible by cooperation programmes between the Austrian Academy of Sciences and the Tibetan Academy of Social Sciences (TASS) in 2002-2005. It was funded by the Austrian Wittgenstein Project 2000 (in 2001) and the International Office of the University of Vienna in 2003. I collected further data during my studies at Tibet University in the academic year 2011/2012 and during a short stay in Lhasa in 2017 for the completion of my dissertation on Geser bards.

This article is dedicated to my late professor Kaethe Uray-Koehalmy who inspired my studies on the Geser epic. I also wish to thank the researchers of the Tibet University and TASS in Lhasa. My warmest thanks go to the many informants who I contacted during my stays in Tibet. I am also indebted to Dennis Johnson for correcting my English writing. 
bards (lha 'bab sgrung mkhan) by opening their energy channels (rtsa sgo phye ba). Such bardic abilities are passed on within families (brgyud sgrung) and through Tibetans who have a karmic connection with the heroes and heroines of the Geser epic, while other bards seem to have a connection to the local lineage of their religious specialists who are of help to the bards. In their performances they act as bardic mediums by embodying the heroes of the epic and through singing verses in the first person, while the narrated parts are rendered in prose in the third person. Certain ritual paraphernalia are mostly held to be indispensable for performing the epic, such as a bard's hat (zhwa sgrung), a coat, or an even surface like an empty sheet of paper or a small circular mirror (pra phab sgrung). These bards exhibit an awareness of the cosmology of the surrounding landscape and they often include this as part of their performances. They reactivate, manifest, and reproduce a Tibetan cosmos which must be maintained in balance and which is revised in each performance. Inevitable for their practice is a special occasion, a sponsor, and an audience. At the beginning of each performance, the bards invoke and thus introduce the heavenly gods, the local deities, and the spirits of the underworld to their audience. Only after doing so are they able to start their bardic presentations, which therefore also contribute to a lasting balance of the three realms. One outcome of this research is that fortunate circumstances and the support of the religious specialists involved often play a vital role in the enhancement of the repertoire of bardic performances. Some bardic mediums are also able to practice as healers and diviners (dpa' bo / dpa' mo or lha pa) [Berglie 1996].

My findings document an increasing institutional and academic incorporation of the bards following the placement of the Geser epic and its bards on the UNESCO Intangible Heritage List in the PRC in 2009. In 2011, the National Social Science Fund enforced general surveys, including the registration of the bards and the establishment of a database on the written versions of the epic, as well as the context in which they were created [CICH 2017, Wangdan 2017: 66-67]. Currently, there is only one active visionary bard employed at the Tibet University in Lhasa. Around ten visionary bards are affiliated with the People's Art Institute of the Nagchu Prefecture, one with a permanent position. They are requested to perform in public as for example at festivals, such as the one in Nagchu, which has been renamed to "Annual Geser Festival - Chang Thang Geser Horse-Racing Cultural and Commercial Tourist Festival" in 2015.

Next to the state-controlled strains of oral transmission, there also remains an alternative and unofficial strain. In the last decades, the overall number of those mostly illiterate bards in the Chamdo and Nagchu Prefectures has slightly increased up to approximately 80 . The exact amount of the few visionary bards amongst them cannot be traced. They are tolerated by the ruling government, since they are regarded as more favourable in their current roles as bardic mediums than in their alternative roles as healers and diviners. Furthermore, forms of transmission of the epic that are not visionary are encouraged. In this way, bardic performances have become strongly folklorised and commercialised with professional actors in festivals and TV productions. Thus, like the epic itself, the transmitters of the Geser epic too have become increasingly appropriated.

All in all, in the twenty-first century, the Geser epic stands as the most widely researched epic in the PRC, while bards continue to place their epic king Geser on stage. At this time, it seems unpredictable whether the bardic oral transmission of the epic will continue to be vital to the Tibetan audiences or whether the numerous publications of the epic will persevere its transmission. Even if it remains to be seen which forms the epic king will assume in the future, he will certainly remain important to Tibetans.

\section{Bibliography}

1. Berglie P.-A. Spirit-Mediums and the Epic. Remarks on Gesar and the Epic among Spirit-Mediums in Tibet and Ladakh // Shaman Journal of International Society for Shamanic Research 4/1-2. Szeged, 1996. P. 17-29.

2. CICH (China Intangible Cultural Heritage) (ed.) Rgyal yong rig gnas mnyam spyod las gzhi'i bod skad thon khungs 'dzugs skyong tha gnas (National Cultural and Performance Cooperation Heritage Project Establishing the Origins of Tibetan Language). Volume 1: 360 Gesar Songs, Volume 2 and 3: DVD Collection of Gesar Performances. Lhasa, 2017.

3. Gcod pa D. Gling ge sar sgrung gi dka' gnad gsal ba'i sgron me. Xining, 2000. 263 p.

4. Diemberger H. Female Oracles in Modern Tibet, // Gyatso, Janet and Havenik, Hanna (eds.) Women in Tibet, London, 2005. P. 113-168.

5. Rgyal mtsho 'J. The Singers of the King Gesar Epic // Honko, Lauri (ed.) Religion, Myth, and Folklore in the World's Epics. Berlin, 1990. P. 471-484.

6. Jabb L. Oral and Literary Continuities in Modern Tibetan Literature: The Inescapable Nation. London, 2015. $288 \mathrm{p}$. 
7. Nebesky-Wojkowitz R. A Report on Ethnographical Research in the Sikkim Himalayas 1950-1953 // Wiener Völkerkundliche Mitteilungen 2/1. Völkerkundliche Arbeitsgemeinschaft in der Anthropologischen Gesellschaft Wien. 1954. P. 33-38.

8. Stein R. A. Recherches sur l'épopée et le bard. Paris, 1959. 646 p.

9. Studer E The Epic King on Stage - an Anthropological Study on the Performers of the Tibetan Gesar Epic in their Historical and Contemporary Contexts. Dissertation Vienna, 2020. 259 p.

10. Wangdan N. The Agglomeration of Tibetan Oral Tradition: Gesar // Tibetan Literature (translated by Zuo, Yangyang and Zhao, Xiaoxue). Beijing, 2017. P. 33-67.

11. Yang E. On the Artists Who Perform the Epic 'King Gesar' // First International Symposium on Gesar Epic Studies, Chengdu, 1989.

12. Yang E. Singer and Storyteller in Gesar Epic Tradition: A Follow-Up Study (in Chinese). Beijing, 2017. 336 p. 